\title{
Chlamydia trachomatis and cervical intraepithelial neoplasia in married women in a Middle Eastern community
}

M. Valadan, ${ }^{7}$ F. Yarandi, ${ }^{1}$ Z. Eftekhar, ${ }^{7}$ S. Darvish, ${ }^{1}$ M.S. Fathollahi ${ }^{2}$ and A. Mirsalehian ${ }^{3}$

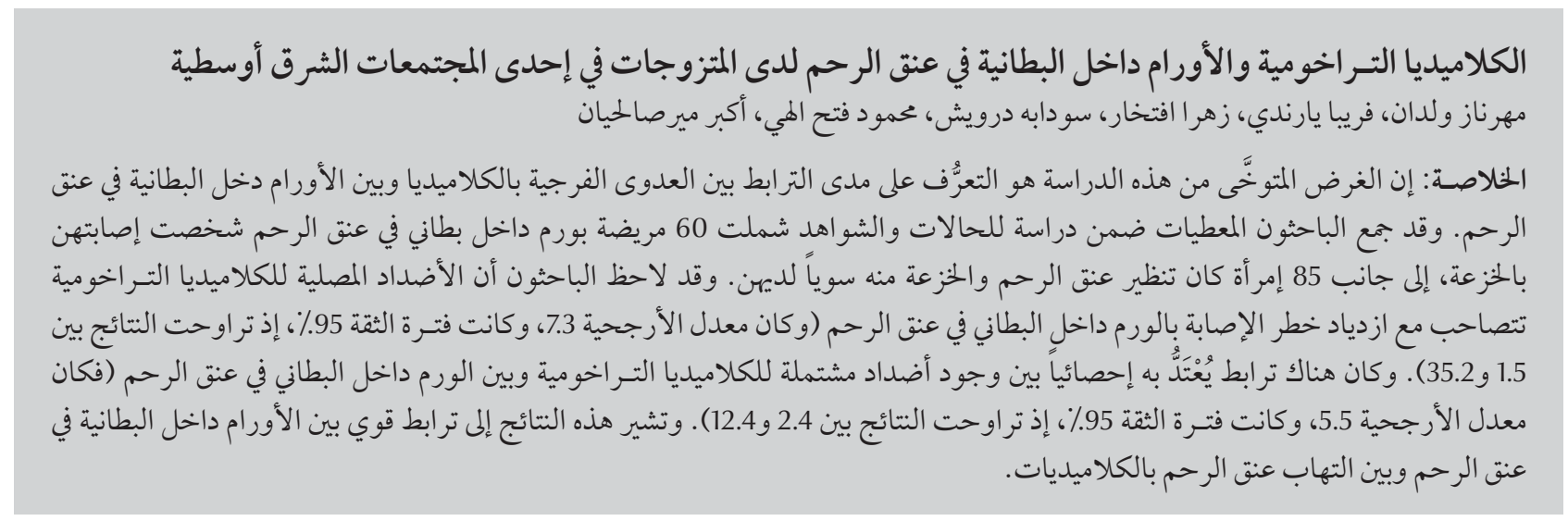

ABSTRACT The objective of this study was to determine the association between vaginal Chlamydia infection and cervical intraepithelial neoplasia (CIN). Data were collected in a case-control study for 60 patients with CIN in biopsy and 85 control subjects with normal colposcopy and biopsy. Serum antibodies to C. trachomatis were associated with an increased risk for $\mathrm{CIN}$ [odds ratio $(\mathrm{OR})=7.3 ; 95 \%$ confidence interval $(\mathrm{CI}) 1.5-35.2)]$. There was also a significant association between presence of inclusion bodies for $C$. trachomatis and $\mathrm{CIN}(\mathrm{OR}=5.5 ; 95 \% \mathrm{CI}$ 2.4-12.4). These results indicate a strong association between $\mathrm{CIN}$ and chlamydial cervicitis.

Les infections à Chlamydia trachomatis et la néoplasie cervicale intraépithéliale chez les femmes mariées d'une communauté du Moyen-Orient

RÉSUMÉ L'objectif de cette étude était de déterminer la relation entre les infections vaginales à Chlamydia et la néoplasie cervicale intraépithéliale (CIN). Des données ont été collectées lors d'une étude cas-témoin portant sur 60 patientes dont la biopsie confirmait une CIN et un groupe témoin de 85 personnes dont la colposcopie et la biopsie étaient normales. Les anticorps sériques anti-C. trachomatis étaient associés à une augmentation du risque de $\mathrm{CIN}$ (odds ratio $=7,3$; intervalle de confiance (IC) $95 \%$ 1,5 - 35,2)]. Une association significative a également été observée entre la présence de corps d'inclusion de C. trachomatis et la CIN (odds ratio=5,5 ; IC 95 \% 2,4 -12,4). Ces résultats indiquent une association importante entre la CIN et une cervicite à Chlamydia.

${ }^{7}$ Department of Obstetrics and Gynaecology, Mirza Koochak Khan Hospital; ${ }^{2}$ Department of Biostatistics; ${ }^{3}$ Department of Pathology, Tehran University of Medical Sciences, Tehran, Islamic Republic of Iran (Correspondence to M. Valadan:mehrnaz_valadan@yahoo.com).

Received: 30/10/07; accepted: 11/02/08 


\section{Introduction}

Infection with Chlamydia trachomatis, a highly prevalent sexually transmitted agent worldwide, is mostly asymptomatic (70\%-80\%) and often remains undetected. Besides causing cervicitis and urethritis, infection may result in serious secondary complications such as pelvic inflammatory disease and pelvic pain, tubal infertility and ectopic pregnancy [1]. In addition, $C$. trachomatis has been suggested to be a cofactor in the development of cervical cancer $[2,3]$. However, in some studies no association was found between C. trachomatis and cervical neoplasia [4].

The objective of this study was to determine the association between vaginal chlamydial infection and cervical intraepithelial neoplasia (CIN).

\section{Methods}

For this retrospective case-control study, participants were selected from the total of 609 women visiting the gynaecology clinic in our hospital between January 2002 and May 2003 and who were referred to the colposcopy clinic at Mirza Koochak Khan Hospital, Tehran. Colposcopy showed suspicious/abnormal cervix in 200 women and biopsy was taken for them. Since many of the patients had been referred from other cities, 20 patients were not available. From the 180 remaining, we selected 60 patients with CIN in biopsy and 85 control subjects with normal colposcopy and biopsy after statistically matching for age and social status. We used the Bethesda system for classification of CIN.

Each participant was tested for C. trachomatis using 2 methods: 1) an immunuofluorescence technique to measure specific antichlamydial IgGantibody in blood samples (titres of $\geq 1 / 64$ were considered positive for C. trachomatis); and 2) Giemsa staining for detecting inclusion bodies characteristic of $C$. trachomatis.

Each participant completed a detailed questionnaire administered by a trained interviewer covering demographic data, general health, obstetrical and gynaecological history and other risk factors. All participants gave written informed consent to write their participation.

\section{Statistical methods}

Categorical variables were summarized by absolute frequencies and percentages and were compared using chi-squared or Fisher exact test, as appropriate. In order to evaluate the association of C. trachomatis with CIN, both crude and Mantel-Hansel odds ratio (OR), adjusted for possible confounders, with 95\% confidence interval, were calculated. For the statistical analysis SPSS, version 13.0 for Windows, was used. All $P$-values were 2 -tailed, with statistical significance defined at $P \leq 0.05$.

\section{Results}

All participants were married and the age range was $20-65$ years: 28 in the patient group and 33 in the control group were over 40 years old.

The overall prevalence of positive serum antibodies for C. trachomatis infection for cases and controls together was $26.2 \%$ (Table 1); $45.0 \%$ among women with CIN and $12.9 \%$ among controls, which was a highly significant difference $(P<0.001$, unadjusted OR $=5.5)$. In addition, the prevalence of inclusion bodies for C. trachomatis in the CIN group was higher than in the control group ( $15.0 \%$ vs $2.4 \%, P=0.005$, unadjusted $\mathrm{OR}=7.3$ ). Participants negative for anti-Chlamydia antibody also had a negative evaluation for $C$. trachomatis inclusion bodies.

Of the CIN group and controls, $76.7 \%$ and $51.8 \%$ respectively had their first sexual contact at age $\leq 20$ years, a statistically significant difference $(P$ $=0.002$ ). In addition, $30.0 \%$ of the women in the CIN group and $10.6 \%$

\begin{tabular}{|c|c|c|c|c|c|c|}
\hline \multirow[t]{2}{*}{ Variable } & \multicolumn{2}{|c|}{$\begin{array}{l}\text { Women with CIN } \\
\qquad(n=60)\end{array}$} & \multicolumn{2}{|c|}{$\begin{array}{l}\text { Controls } \\
(n=85)\end{array}$} & \multirow[t]{2}{*}{$P$-value } & \multirow[t]{2}{*}{ Crude OR $(95 \% \mathrm{Cl})$} \\
\hline & No. & $\%$ & No. & $\%$ & & \\
\hline Positive C. trachomatis IgG & 27 & 45.0 & 11 & 12.9 & $<0.001$ & $5.5(2.4-12.4)$ \\
\hline Presence of inclusion body & 9 & 15.0 & 2 & 2.4 & 0.005 & $7.3(1.5-35.2)$ \\
\hline First sexual contact $<20$ years & 46 & 76.7 & 44 & 51.8 & 0.002 & $3.1(1.4-6.3)$ \\
\hline First pregnancy $\leq 16$ years & 18 & 30.0 & 9 & 10.6 & 0.003 & $3.6(1.4-8.7)$ \\
\hline Multiparity & 36 & 60.0 & 35 & 41.2 & 0.02 & $2.1(1.1-4.2)$ \\
\hline History of abortion & 31 & 51.7 & 25 & 29.4 & 0.007 & $2.6(1.2-5.1)$ \\
\hline Used OCP for $\geq 1$ year & 22 & 36.7 & 22 & 25.9 & 0.1 & $1.6(0.8-3.3)$ \\
\hline History of genital infection & 42 & 70.0 & 42 & 49.4 & 0.01 & $2.4(1.1-4.7)$ \\
\hline
\end{tabular}

$C I N=$ cervical intraepithelial neoplasia; $O R=$ odds ratio; $C l=$ confidence interval. $O C P=$ oral contraceptive pills. 
in the control group had their first pregnancy at age $\leq 16$ years $(P=0.003)$, again a statistically significant difference. There was a history of genital tract infection in $70.0 \%$ of cases compared with $49.4 \%$ of controls $(P=0.01)$. Use of oral contraceptive pills for $\geq 1$ year was not significantly different between the 2 groups $(P=0.1)$.

None of the women in this study had a history of cigarette smoking, therefore the association of smoking with CIN was not evaluated. Furthermore, we could not assess the relationship between CIN and number of sexual partners, because sexual relations outside marriage are punishable by law in the Islamic Republic of Iran, and this is why our specimen was taken from married women only.

Of the 60 women with CIN, 54 were diagnosed with CINI, 3 had CINII and 3 had CINIII. The prevalence of serum antibodies positive for $C$. trachomatis was 22 (41\%) for CINI, 3 (100\%) for CINII and 2 (66\%) for CINIII.

The association of C. trachomatis and CIN remained significant after adjustment for first sexual contact $<20$ years, first pregnancy $\leq 16$ years, multiparity, history of abortion and genital infection (Table 2).

\section{Discussion}

We found a significant association between CIN and the presence of $C$. trachomatis $\operatorname{IgG}$ (crude $\mathrm{OR}=5.5$ ) and the presence of inclusion bodies for C. trachomatis (crude OR $=7.3$ ), which remained significant after adjusting for other risk factors. Schachter et al. also reported a significant excess of antibodies against $C$. trachomatis in women with cervical neoplasia compared to

\begin{tabular}{lc}
\hline $\begin{array}{l}\text { Table } 2 \text { Odds ratio (OR) for Chlamydia trachomatis infection in cases with CIN } \\
\text { after adjustment for other risk factors }\end{array}$ \\
\hline Risk factor adjusted for: & Adjusted OR (95\% CI) \\
\hline First sexual contact < 20 years & $5.4(2.3-12.7)$ \\
First pregnancy $\leq 16$ years & $5.0(2.1-11.5)$ \\
Multiparity & $5.1(2.2-10.9)$ \\
History of abortion & $4.5(1.9-10.5)$ \\
History of genital infection & $5.0(2.2-11.1)$ \\
\hline
\end{tabular}

$C I N=$ cervical intraepithelial neoplasia $; C l=$ confidence interval.

controls [5]. Moreover, Koskela et al. found that the presence of $C$. trachomatis antibodies was associated with an increased risk of cervical squamous cell carcinoma [6]. Wallin et al. reported a similar association in a Swedish study [7]. However, there are a number of studies with opposing results. In a study on 128 women with clinical signs of cervicitis, genital chlamydial infection did not directly influence the development of CIN [4].

Our study does provide information on this association in relation to this part of the world. To our knowledge, this is one of a few reports on the association between cervical abnormalities and $C$. trachomatis infection from the Middle East. However, when interpreting the results, many points need to be borne in mind:

- Ours is an exceptional population, in which the prevalence of both cervical abnormalities and C. trachomatis infection are low.

- Our sample included a greater number of older women compared with the majority of studies published in Western countries.

- This study only addressed the association between cervical abnormalities and C. trachomatis infection, and not between frank cancers and C. trachomatis infection.
- We had limited statistical power related to the number of cases of CINII/ CINIII, leading us to combine them.

- Lastly, we did not evaluate human papilloma virus (HPV). It is possible that concurrent infection with HPV may exacerbate the effect of Chlamydia infection on cervical cells.

Discrepancies between our results and those from studies conducted elsewhere may be related to differences in the characteristics of the studied populations (such as age, patterns of sexual behaviour or openness in reporting sexual behaviour).

Our results show that chlamydial cervicitis is a strong risk factor for CIN. The link between bacterial infections and carcinogens is not clear, but genetic damage and neoplastic changes can be induced in vitro by co-culturing cells. Release of nitric oxide occurs in C. trachomatis infections. Recent evidence has also shown that C. trachomatis inhibits host cell apoptosis; these mechanisms could initiate or promote cervical carcinogens [8]. This study was a preliminary attempt to establish the prevalence of cervical abnormalities and chlamydial infection, and the association between the 2 in a low-prevalence, Middle Eastern population. Further research is needed to investigate the apparent association between CIN and C. trachomatis infection.

\section{References}

1. Paavonen J, Eggert-Kruse W. Chlamydia trachomatis: impact on human reproduction. Human reproduction update, 1999, 5:433-47.
2. Fischer N. Chlamydia trachomatis infection in cervical intraepithelial neoplasia and invasive carcinoma. European journal of gynaecological oncology, 2002, 23(3):247-50. 
3. Hakama M et al. Serum antibodies and subsequent cervical neoplasms: a prospective study with 12 years of follow-up. American journal of epidemiology, 1993, 137:166-70.

4. Borisov I, Mainkhard K. The relationship between genita chlamydial infection and the presence of cervical intraepithelial neoplasia. Akush ginecol (Sofia), 1995, 34(3):39-40.

5. Schachter J et al. Chlamydia trachomatis and cervical neoplasia. Journal of the American Medical Association, 1982, 248:2134-8.
6. Koskela P et al. Chlamydia trachomatis infection as a risk factor for invasive cervical cancer. International journal of cancer, 2000, 85:35-9.

7. Wallin KL et al. A population-based prospective study of Chlamydia trachomatis infection and cervical carcinoma. International journal of cancer, 2002, 101(4):371-4.

8. Anttila T et al. Serotypes of Chlamydia trachomatis and risk for development of cervical squamous cell carcinoma. Journal of the American Medical Association, 2001, 285:47-51.

\section{Towards a strategy for cancer control in the Eastern Mediterranean Region}

Towards a strategy for cancer control in the Eastern Mediterranean Region was developed in response to the increasing burden of cancer and the need for coordinated action in this regard. This publication reflects a shared commitment to reducing the incidence of cancer and improving the quality of life of those who develop cancer. By promoting an integrated approach to the provision of cancer control activities and services, it is hoped the publication will encourage and assist government and nongovernmental service providers to work more closely together in addressing cancer control:

Towards a strategy for cancer control in the Eastern Mediterranean Region is targeted at government and nongovernmental agencies whose work impacts on the delivery of cancer services and activities, as well as the wide range of individuals involved in the management and delivery of activities and services related to cancer and people affected by cancer.

The full text of this publication is freely available at: http://www.emro.who.int/dsaf/dsa1002.pdf 